\title{
Delayed Internal Fixation of Femoral Shaft Fracture Reduces Mortality Among Patients with Multisystem Trauma
}

\author{
By Saam Morshed, MD, MPH, Theodore Miclau III, MD, Oliver Bembom, PhD, Mitchell Cohen, MD, \\ M. Margaret Knudson, MD, and John M. Colford Jr., MD, PhD \\ Investigation performed at the Departments of Orthopaedic Surgery and Surgery, University of California at San Francisco, San Francisco, \\ California, and the Division of Epidemiology and Biostatistics, School of Public Health, University of California at Berkeley, \\ Berkeley, California
}

Background: Fractures of the femoral shaft are common and have potentially serious consequences in patients with multiple injuries. The appropriate timing of fracture repair is controversial. The purpose of the present study was to assess the effect of timing of internal fixation on mortality in patients with multisystem trauma.

Methods: We performed a retrospective cohort study with use of data from public and private trauma centers throughout the United States that were reported to the National Trauma Data Bank (version 5.0 for 2000 through 2004). The study included 3069 patients with multisystem trauma (Injury Severity Score, $\geq 15$ ) who underwent internal fixation of a femoral shaft fracture. The time to treatment was defined in categories as the time from admission to internal fixation: $t_{0}$ (twelve hours or less), $t_{1}$ (more than twelve hours to twenty-four hours), $t_{2}$ (more than twenty-four hours to forty-eight hours), $t_{3}$ (more than forty-eight hours to 120 hours), and $t_{4}$ (more than 120 hours). The relative risk of in-hospital mortality when the four later periods were compared with the earliest one was estimated with inverse probability of treatment-weighted analysis. Subgroups with serious head or neck, chest, abdominal, and additional extremity injury were investigated.

Results: When compared with that during the first twelve hours after admission, the estimated mortality risk was significantly lower in three time categories: $t_{1}$ (relative risk, $0.45 ; 95 \%$ confidence interval, 0.15 to $0.98 ; p=0.03$ ), $t_{3}$ (relative risk, $0.58 ; 95 \%$ confidence interval, 0.28 to $0.93 ; p=0.03$ ), and $t_{4}$ (relative risk, $0.43 ; 95 \%$ confidence interval, 0.10 to $0.94 ; p=0.03$ ). Patients with serious abdominal trauma (Abbreviated Injury Score, $\geq 3$ ) experienced the greatest benefit from a delay of internal fixation beyond twelve hours (relative risk, 0.82 [95\% confidence interval, 0.54 to 1.35] for patients with an Abbreviated Injury Score of $<3$, compared with 0.36 [95\% confidence interval, 0.13 to 0.87 ] for those with an Abbreviated Injury Score of $\geq 3$ ) ( $p$ value for effect modification, 0.09 ).

Conclusions: Delayed repair of femoral shaft fracture beyond twelve hours in patients with multisystem trauma, which may allow time for appropriate resuscitation, reduces mortality by approximately 50\%. Patients with serious abdominal injury benefit most from delayed treatment. These results support delaying definitive treatment of long-bone injuries in patients with multisystem trauma as a means of so-called damage-control in order to reduce adverse outcomes.

Level of Evidence: Therapeutic Level III. See Instructions to Authors for a complete description of levels of evidence.

Disclosure: In support of their research for or preparation of this work, one or more of the authors received, in any one year, outside funding or grants in excess of $\$ 10,000$ from the Orthopaedic Research and Education Foundation (OREF), the Association Internationale Pour L'Osteosynthese Dynamique (AIOD) (\#100805-SMTM), and the National Institutes of Health. Neither they nor a member of their immediate families received payments or other benefits or a commitment or agreement to provide such benefits from a commercial entity. No commercial entity paid or directed, or agreed to pay or direct, any benefits to any research fund, foundation, division, center, clinical practice, or other charitable or nonprofit organization with which the authors, or a member of their immediate families, are affiliated or associated.

eC A commentary is available with the electronic versions of this article, on our web site (www.jbjs.org) and on our quarterly CD-ROM/DVD (call our subscription department, at 781-449-9780, to order the CD-ROM or DVD). 
The Journal of Bone \& Joint Surgery - JBjS. org VOlume 91-A · NUmber 1 · JanUary 2009
Delayed Fixation of Femoral Shaft Fracture in Multisystem Trauma Patients
D he optimal timing of long-bone fracture fixation in patients with multisystem trauma is controversial. Several observational studies ${ }^{1-8}$ and one randomized study ${ }^{9}$ have suggested that early stabilization of major long-bone fracturesthose of the shaft of the femur being most common-is associated with clinical benefits in terms of reducing the incidence of pulmonary complications and mortality. Other studies have suggested that internal fixation of long-bone fractures, either with intramedullary nailing or plate osteosynthesis, may have potentially deleterious effects in the acute setting, when systemic hypoperfusion ${ }^{10}$ and inflammation ${ }^{11-13}$ may increase susceptibility to end-organ injury and increase morbidity. A meta-analysis ${ }^{14}$ demonstrated a large relative risk reduction (relative risk, 0.30; $95 \%$ confidence interval, 0.22 to 0.40 ) in respiratory complications in association with early operative fixation (usually within twenty-four hours), whereas two systematic reviews ${ }^{15,16}$ demonstrated no difference in morbidity or mortality between early operative treatment (usually at less than twenty-four hours) and late operative treatment of femoral shaft fractures, either overall or within subgroups of patients with associated head injuries or thoracic injuries. These inconsistent findings have left clinicians debating what effect definitive fracture care has on adverse outcomes. Differences in treatment definition (both in terms of time cutoffs and the type of fixation used), the inclusion of small samples limited to single institutions, and inadequate control of confounding variables all serve to limit the validity and generalizability of previous findings. We studied the effect of the timing of definitive care of femoral shaft fractures with use of a multilevel definition of treatment time drawn from the largest available multicenter database of patients with multisystem trauma (the National Trauma Data Bank).

\section{Materials and Methods}

Study Cohort and Data Source

We identified our study cohort with use of the National Trauma Data Bank (version 5.0), which draws from 567 trauma centers from around the United States ${ }^{17}$ and contains nearly one million incident trauma cases that occurred over the five-year period between January 1, 2000, and December 31, 2004. The National Trauma Data Bank contains prehospitalization and hospitalization information compiled from medical records during admission (including injury characteristics, comorbidities, inpatient treatments, and outcomes), which are submitted to the American College of Surgeons for quality control and maintenance.

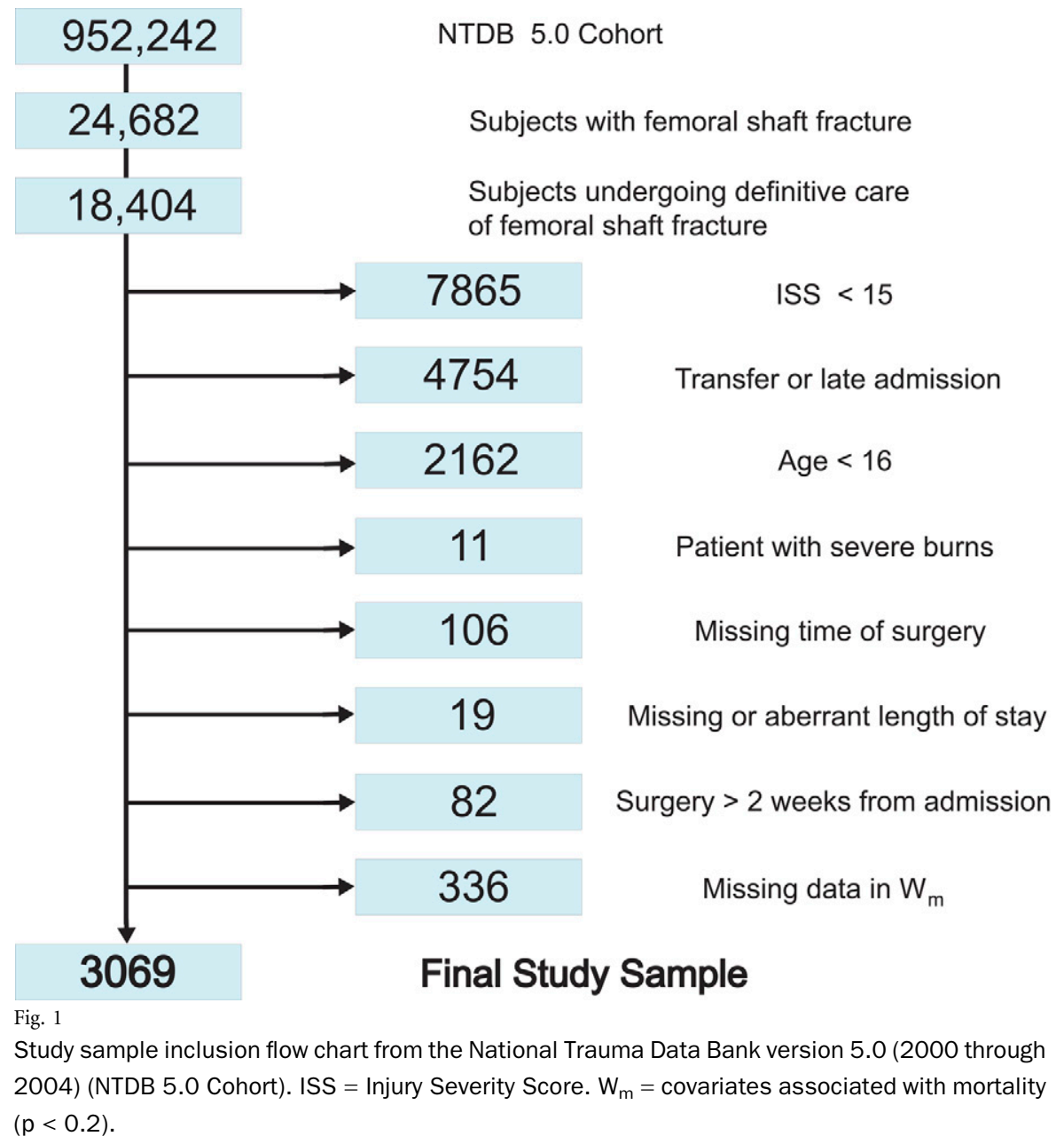


The Journal of Bone \& Joint Surgery $\cdot$ JBjS.org VOLUME 91-A · NUMBer 1 - JANUARY 2009

Delayed Fixation of Femoral Shaft Fracture in Multisystem Trauma Patients

TABLE I Summary Table of Bivariate Associations of Covariates with Mortality and Treatment Group

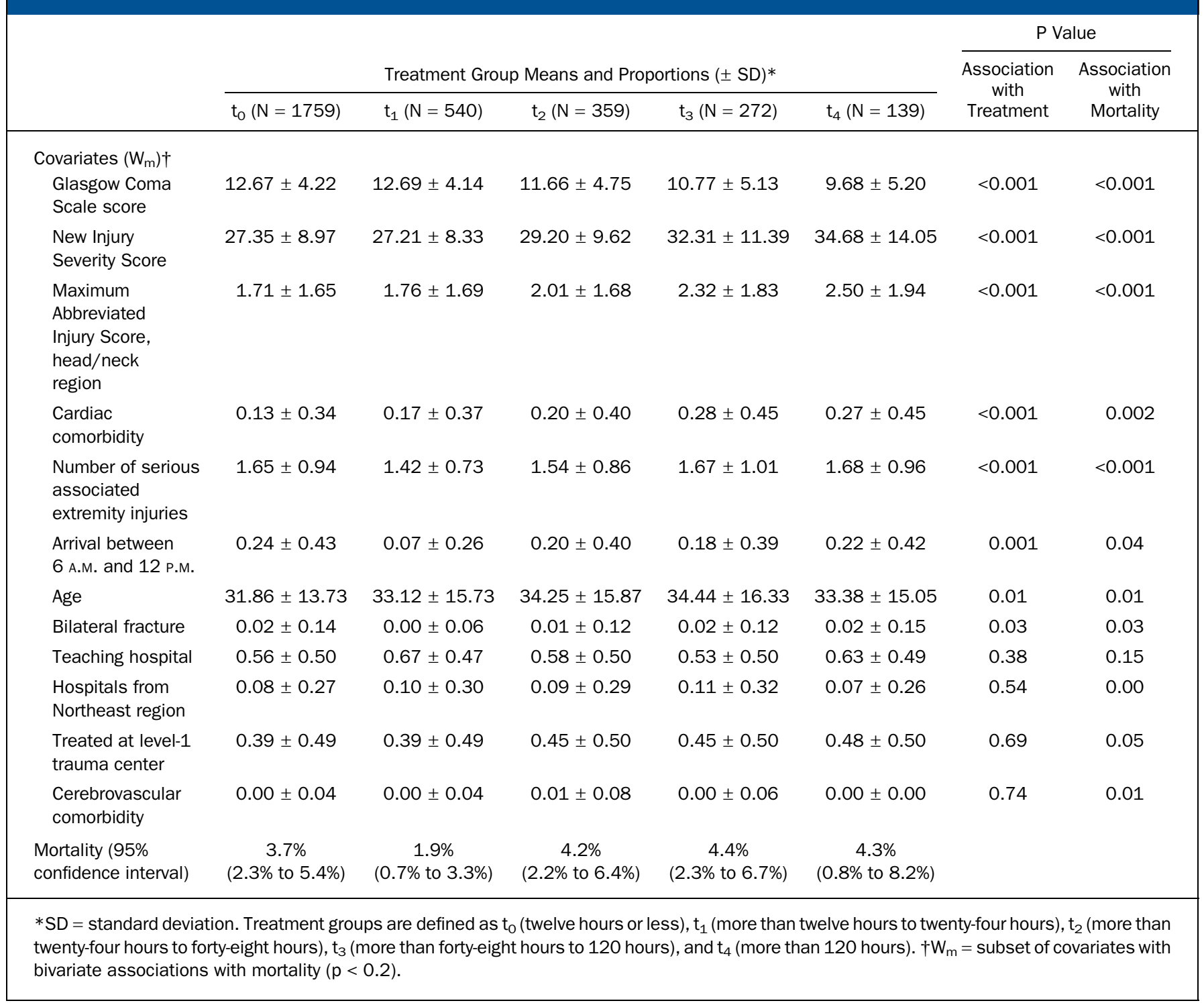

We included patients in our study sample if they (1) had a closed or open fracture (or fractures) of the femoral shaft as identified by an International Classification of Diseases, Ninth Revision, Clinical Modification (ICD-9-CM) diagnostic code of 821.0 (fracture of femoral shaft/not otherwise specifiedclosed), 821.01 (fracture of femoral shaft-closed), 821.1 (fracture of femoral shaft/not otherwise specified-open), or 821.11 (fracture of femoral shaft-open); (2) had an International Classification of Diseases-derived Injury Severity Score ${ }^{18,19}$ of $\geq 15$; (3) were sixteen years of age or older; and (4) underwent a definitive treatment procedure involving internal fixation of the femur as identified by an ICD-9-CM procedure code of 78.55 (internal fixation-femur), 79.15 (closed reduction and internal fixation-femur), or 79.35 (open reduction and internal fixation-femur). A patient was excluded from the study sam- ple if (1) the patient was received in transfer or was not admitted on the day of injury; (2) the record lacked information on the time from admission to definitive fracture fixation, mortality status, or length of hospitalization; (3) the patient had an associated burn; or (4) the fracture was not definitively fixed within two weeks after admission.

Because of the potential for treatment selection bias in an observational study, we chose to include only subjects with complete information on potentially relevant confounding covariates. An a priori list of baseline covariates available in the National Trauma Data Bank 5.0 was generated on the basis of the literature and clinical suspicion as potential confounders of the relationship between treatment time and mortality. These covariates included age, sex, race, maximum Abbreviated Injury Score $^{18}$ for each of the six anatomic regions (head/neck, face, 


\section{TABLE II Most Common Associated ICD-9-CM-Coded Injuries of the Head or Neck, Chest, Abdomen, and Extremities or Pelvis*}

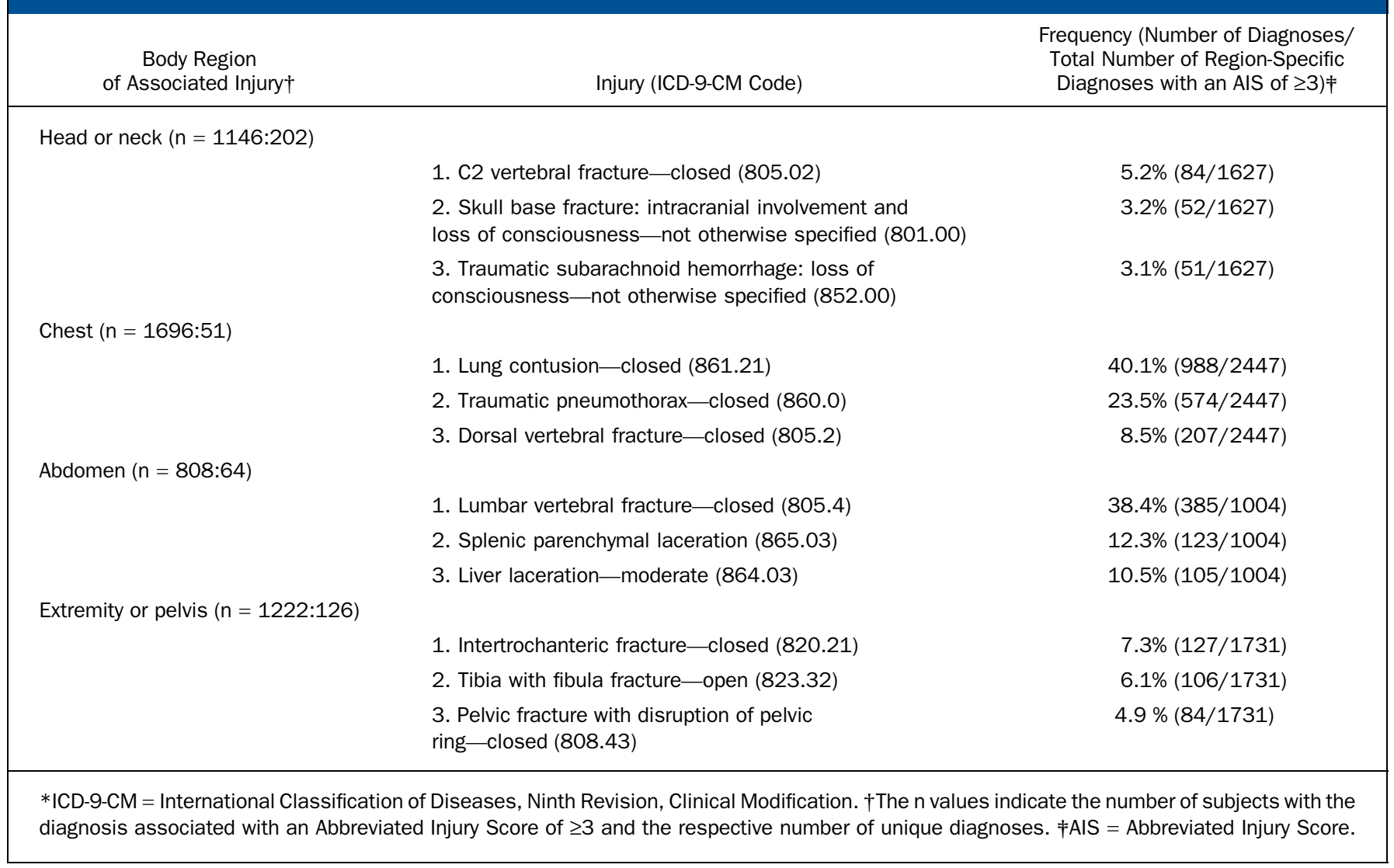

chest, abdomen, extremity/pelvis, and skin), New Injury Severity Score ${ }^{20,21}$, Glasgow Coma Scale score on arrival, first systolic blood pressure, blunt or penetrating trauma, the type of femoral fracture (open or closed), the number of femoral fractures, the number of serious extremity/pelvic injuries (Abbreviated Injury Score, $\geq 3$ ), the presence of alcohol or drugs in the bloodstream at the time of admission, the year of the incident, the time of arrival at the hospital (day divided into four quarters), the modified Charlson comorbidity index ${ }^{22}$, and the presence or history of specific comorbidities (coronary artery disease, including heart failure; chronic obstructive pulmonary disease; stroke; hematologic disease, including coagulopathy; diabetes; pregnancy; or hepatorenal disease or failure) at the time of admission. Hospital characteristics included the mean number of femoral shaft fractures admitted to the treating facility per year, teaching status, type of facility (public or private), American College of Surgeons trauma center level, and geographic region of the United States (Northeast, Midwest, South, West). We then identified a subset of these covariates $\left(\mathrm{W}_{\mathrm{m}}\right)$ associated with mortality $(\mathrm{p}<0.2)$ with use of appropriate nonparametric bivariate tests of association, adjusted for multiple testing with the Benjamini-Hochberg procedure ${ }^{23}$, and excluding observations with missing values in $\mathrm{W}_{\mathrm{m}}$, in order to obtain a final sample with complete data in all measured potentially confounding covariates for analysis.

\section{Treatment Variables}

We investigated whether the timing of definitive treatment of femoral shaft fracture affects mortality. In order to provide clinically relevant categories for treatment beyond a simple dichotomy at twelve or twenty-four hours, we chose five time periods a priori on the basis of commonly used cut-points from the literature ${ }^{14,15,24}: t_{0}$ (twelve hours or less), $t_{1}$ (more than twelve hours to twenty-four hours), $t_{2}$ (more than twenty-four hours to fortyeight hours), $t_{3}$ (more than forty-eight hours to 120 hours), and $t_{4}$ (more than 120 hours). While twenty-four hours is the most commonly used threshold before which "early" treatment has been described in previous studies, we defined our referent group $\left(t_{0}\right)$ as treatment within the first twelve hours in order to represent those subjects who were most likely to have been inadequately resuscitated and in a state of occult hypoperfusion ${ }^{10,25}$. We hypothesize that additional physiologic stress from definitive fracture surgery in such patients could activate an adverse systemic response leading to end-organ injury, multiple organ failure, and excess mortality when compared with the findings in patients managed later, when adequate resuscitation is more likely to have been achieved.

Each procedure in the dataset is recorded with a number of days, hours, and minutes after admission when it was performed. Using this information, we calculated the time from admission to definitive fracture fixation, as defined above with 


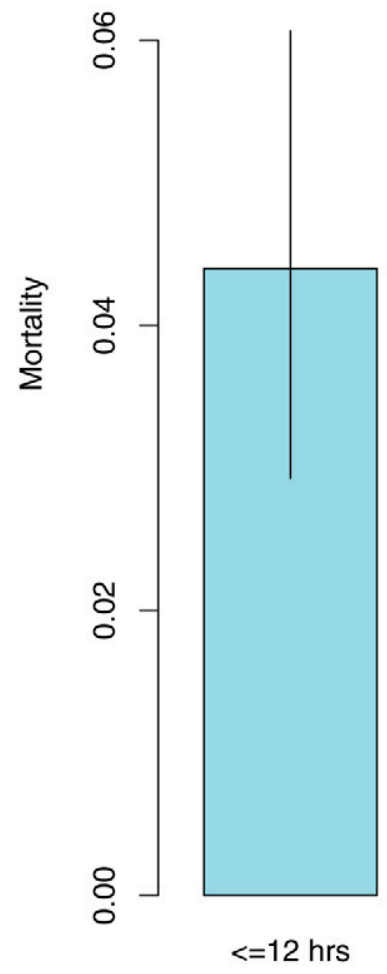

Fig. 2
Inverse

Time of fracture fixation

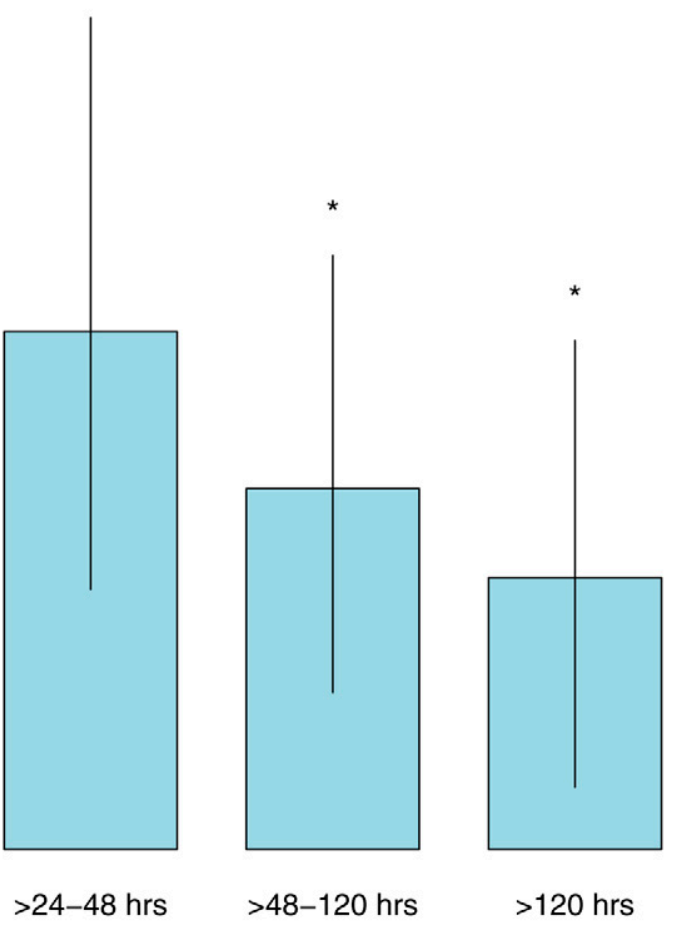

represents significant relative risk reduction $(p<0.05)$ in comparison with the referent $\left(t_{0}\right)$ treatment group (the group that was treated at twelve hours or less).

use of ICD-9-CM procedure codes. By excluding patients who were transferred from other facilities or were admitted one or more days after the injury, we assumed that the calculated treatment time level was a reliable surrogate for the time from the injury, underestimating the true elapsed time only by the time required to reach the hospital.

\section{Main Outcome Measure}

In-hospital mortality was our sole outcome of interest. While other studies of treatment time effect have focused on the diagnosis of acute respiratory distress syndrome (ARDS) or multiple-organ failure, the reporting of such outcomes is inherently subjective and prone to measurement error ${ }^{26}$. Moreover, one could not expect that such outcomes would be validly or reliably measured over such a large number or diverse range of treating centers. Other surrogate measures such as the length of hospital stay are notoriously positively skewed ${ }^{27,28}$, making the effect of timing difficult to analyze and interpret. In the absence of patient-centered outcomes (i.e., health-related quality of life) and systematic assessment of morbid events after treatment, mortality is the most objective, and therefore likely valid, end point. While potentially lacking sensitivity in the detection of morbid consequences of treatment, mortality can be considered a very specific surrogate for clinically important morbidity.

\section{Statistical Methods}

The primary analytical strategy was based on marginal structural models using inverse probability of treatment-weighted estimators $^{29}$ (see Appendix). This method uses the reciprocal of the conditional probability of a subject receiving an assigned treatment given other covariates as a means of confounding control in order to determine the effect of treatment. Unlike propensity score analysis ${ }^{30,31}$, inverse probability of treatment-weighted analysis can easily be adapted for use with multilevel categorical treatment assignment. The likelihood of treatment within one of the five time categories was estimated with use of data-adaptive model selection ${ }^{32}$, and goodness-of-fit of the model was assessed with use of the Hosmer-Le Cessie test ${ }^{33}$ (see Appendix). We were also interested in the potential for differences of treatment effect (effect modification) for different subgroups defined by the severity of associated head or neck, chest, abdominal, or additional extremity/pelvic injury. Therefore, we tested the hypothesis that patients with serious injuries (defined as an Abbreviated Injury Score ${ }^{34}$ of $\geq 3$ ) in any one of these four anatomic regions would have a greater relative risk reduction with fixation delayed beyond the first twelve hours of hospitalization than those without such associated injuries (see Appendix).

We attempted to select only patients who could plausibly receive treatment during any of the five time categories. Estimates could be severely biased by the inclusion of subjects who, 
The Journal of Bone \& Joint Surgery $\cdot$ JBJS.org VOLUME 91-A · NUMBER 1 J JANUARY 2009

Delayed Fixation of Femoral Shaft Fracture in Multisystem Trauma Patients

TABLE III Comparison of Crude, Regression, and Marginal Structural Model Estimates of Effect of Treatment Time on Mortality

\begin{tabular}{|c|c|c|c|c|}
\hline Estimate & $>12$ to $24 \mathrm{Hr}$ & $>24$ to $48 \mathrm{Hr}$ & $>48$ to $120 \mathrm{Hr}$ & $>120 \mathrm{Hr}$ \\
\hline \multicolumn{5}{|c|}{ Crude relative risk* } \\
\hline Point estimate & 0.50 (0.18 to 1.01$)$ & 1.13 (0.58 to 2.05$)$ & 1.19 (0.67 to 2.03$)$ & 1.17 (0.24 to 2.65$)$ \\
\hline \multicolumn{5}{|c|}{ IPTW relative risk*† } \\
\hline Point estimate & 0.45 (0.15 to 0.98$)$ & 0.83 (0.43 to 1.44$)$ & $0.58(0.28$ to 0.93$)$ & 0.43 (0.10 to 0.94$)$ \\
\hline \multicolumn{5}{|c|}{ Standardized risk ratio*キ } \\
\hline Point estimate & 0.47 (0.14 to 1.11$)$ & 0.94 (0.44 to 1.76$)$ & 0.58 (0.21 to 1.09$)$ & $0.43(0.09$ to 0.94$)$ \\
\hline$P$ value & 0.07 & 0.85 & 0.09 & 0.05 \\
\hline \multicolumn{5}{|c|}{$\begin{array}{l}* \text { The point estimates are given with the } 95 \% \text { confidence intervals in parentheses. For all analyses, the } t_{0} \text { group (treated at twelve hours or less) was used } \\
\text { as the referent group. †Inverse probability of treatment-weighted (IPTW) relative risk estimates were generated using a model for treatment assignment } \\
\text { controlling for the subset of covariates with bivariate associations with mortality }\left(\mathrm{W}_{\mathrm{m}}\right) \text { : New Injury Severity Score, Glasgow Coma Scale score, Northeast } \\
\text { region, age, arrival time, the number of serious extremity/pelvic or head/neck injuries, the number of femoral fractures, the presence of cardiac or } \\
\text { cerebrovascular comorbidities, teaching status, and American College of Surgeons level-1 designation. } ¥ \text { The standardized risk ratio analysis involved the } \\
\text { use of the same treatment model as inverse probability of treatment-weighted analysis but modified weights to give the estimated proportionate risk that } \\
\left.\text { would have been observed if the subjects in the early treatment group (group } t_{0}\right) \text { had received treatment at a later time. }\end{array}$} \\
\hline
\end{tabular}

because of injury severity or other factors, could not have been managed early (within the first twelve hours). Only randomization could achieve an equal probability of treatment within the several treatment categories, so an assumption of experimental treatment assignment must be made when using nonrandomized data in order to make causal inferences. In the Appendix, we present an empirical method for assessing the sensitivity of inverse probability of treatment-weighted estimates to the most likely violation of experimental treatment assignment, specifically, that patients who were managed more than twelve hours after admission could not feasibly have been managed earlier. This approach is based on the standardized risk ratio with use of modified inverse probability of treatmentweighted weights ${ }^{35}$, which, in this case, gives an estimate of the effect of delaying surgery for those subjects who were managed early. If subjects managed after twelve hours vary enough from those managed earlier to bias estimates of effect, the standardized risk ratio-with its target population being the $\mathrm{t}_{0}$ group-should differ from the marginal inverse probability of treatment-weighted estimate. Similarities between the standardized risk ratio and inverse probability of treatment-weighted estimates would support exchangeability of patients in the early treatment group with those managed later and therefore would support the experimental treatment assignment assumptions and the inverse probability of treatment-weighted population estimate. Additionally, in the Appendix, we present the results from a recently proposed quantitative method of checking experimental treatment assignment with use of Monte Carlo simulation $^{36}$.

Confidence intervals and $p$ values were nonparametrically obtained with use of a modified bootstrap approach ${ }^{37,38}$ (see Appendix) that takes into account correlations between patients managed at the same hospital. The level of significance was set at $\mathrm{p}<0.05$. We tested for effect modification by obtaining bootstrap-based $\mathrm{p}$ values for the hypothesis that the relative risk of mortality associated with treatment time is identical for both levels (not serious and serious) defined by each of the four potential effect modifiers discussed above. Because interactions of this kind are difficult to identify, the level at which significance was considered was relaxed to $\mathrm{p}<0.2$. All analyses were carried out with $\mathrm{R}$ software (version 2.3.1) ) $^{39,40}$.

\section{Source of Funding}

Direct support of this work came from a research grant from the AIOD (100805-SMTM), who did not play any role in the design, conduct, analysis, or reporting of this work.

\section{Results}

The National Trauma Data Bank 5.0 included 18,404 sub1 jects with at least one femoral shaft fracture who underwent internal fixation. Figure 1 illustrates how the study sample of 3069 subjects was selected on the basis of inclusion and exclusion criteria. The average age (and standard deviation) was $32.7 \pm 14.7$ years, and 2207 patients $(71.9 \%)$ were men. More than half of the patients $(n=1759)$ were managed within twelve hours after admission, with decreasing numbers being managed in each subsequent time period (Table I). There was a total of 108 deaths in the study sample (mortality, $3.52 \%$ ), and the unadjusted estimate of the mortality risk was lowest for the group of patients who were managed between twelve and twenty-four hours (1.9\%; 95\% confidence interval, $0.7 \%$ to $3.3 \%$ ) and increased for those who were managed later. The Glasgow Coma Scale score, New Injury Severity Score, and maximum Abbreviated Injury Score in the head or neck region were strongly associated $(\mathrm{p}<0.001)$ with both mortality and treatment, with a consistent trend toward more severe injury among patients who were managed later. One thousand, one hundred and forty-six subjects (37.3\%) had 
The Journal of Bone \& Joint Surgery $\cdot$ Jbjs.org Volume 91-A · Number 1 · January 2009
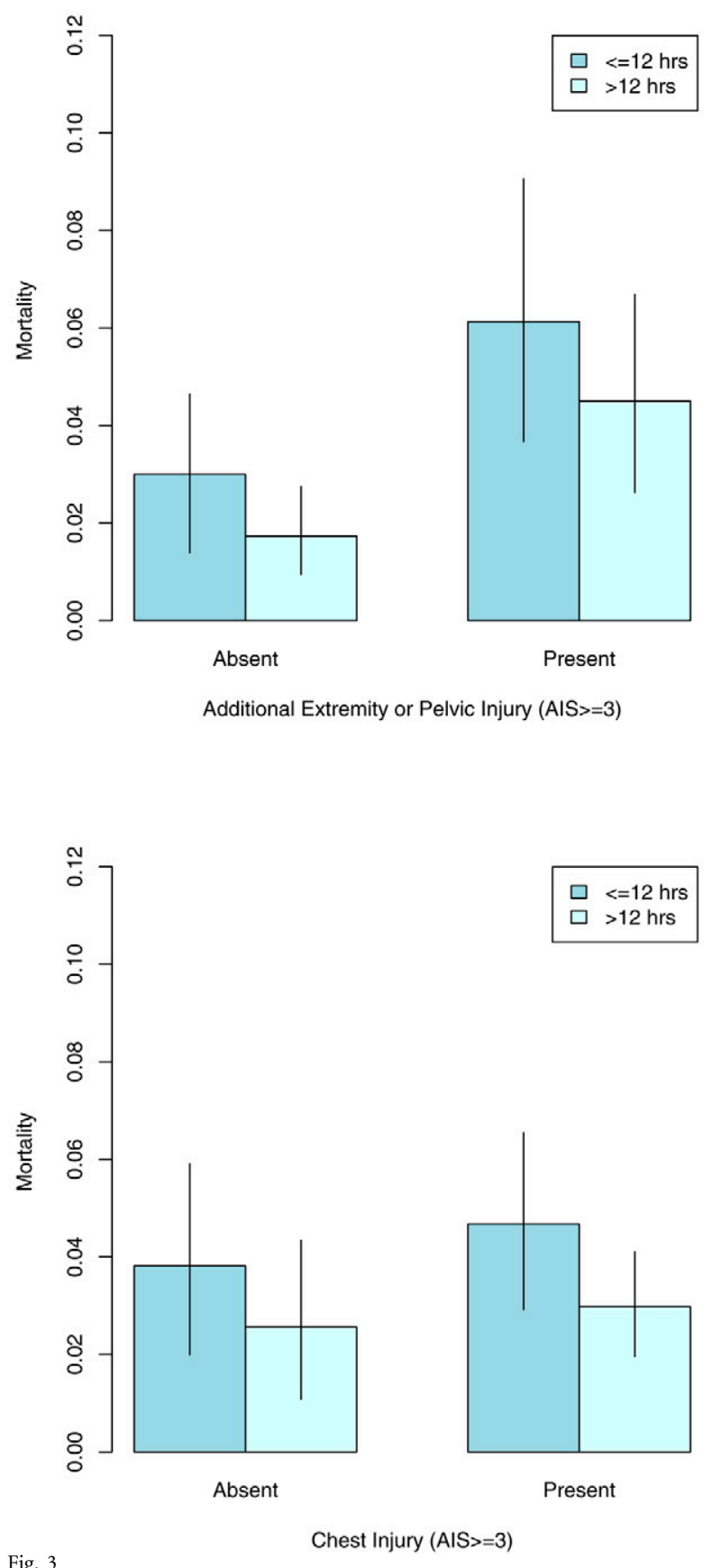

Delayed Fixation of Femoral Shaft Fracture in Multisystem Trauma Patients
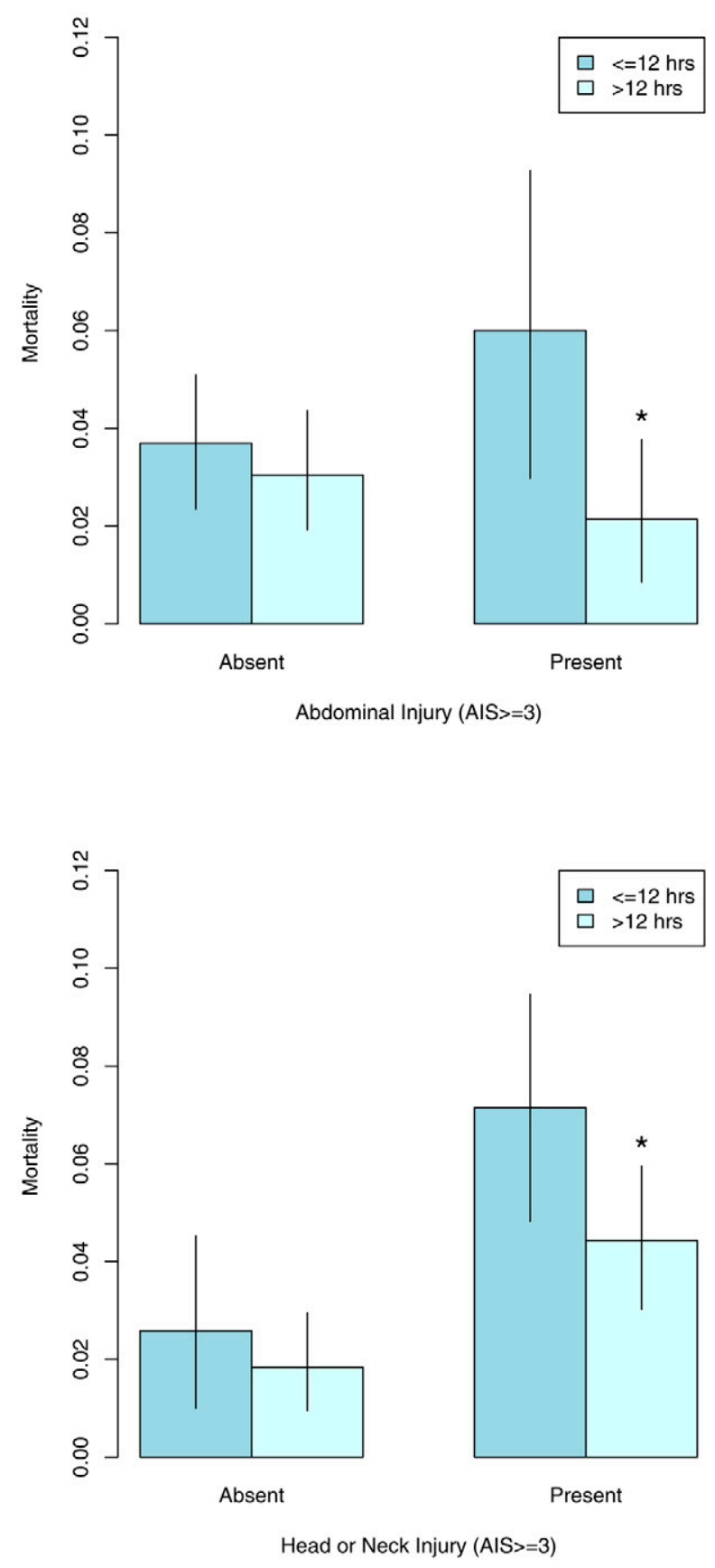

Inverse probability of treatment-weighted mortality estimates, stratified according to the severity of associated injury (presence of serious associated extremity/pelvis, abdominal, chest, and head or neck injury), with $95 \%$ confidence intervals (lines). An asterisk $(*)$ represents significant relative risk reduction $(p<0.05)$ in comparison with the referent $\left(t_{0}\right)$ treatment group. AIS $=$ Abbreviated Injury Score.

associated serious head or neck injuries; 1696 (55.3\%) had associated serious chest injuries; $808(26.3 \%)$ had associated serious abdominal injuries; and $1222(39.8 \%)$ had an additional serious extremity or pelvic injury other than the femoral shaft fracture that was treated (Table II). The most common serious associated injuries, by body region, were closed C2 fracture, pulmonary contusion, lumbar vertebral fracture, and intertrochanteric fracture.
The estimated mortality risk if all subjects had been managed during any one of the five time periods is shown in Figure 2, controlling for measured confounders. Mortality was estimated to be highest if all subjects were managed within twelve hours after admission. If treatment was performed between twelve and twenty-four hours, between forty-eight and 120 hours, or after 120 hours, mortality was estimated to be reduced to between $43 \%$ and $58 \%$ of this reference mortality level (Table III). A mortality 
TABLE IV Inverse Probability of Treatment-Weighted Estimates of the Relative Risk of Mortality Given Treatment Delay (Greater than Twelve Hours) Stratified by Severity of Associated Injury

\begin{tabular}{|c|c|c|c|c|c|}
\hline Associated Injury & $\begin{array}{c}\text { Relative Risk } \\
\text { (95\% Confidence Interval) }\end{array}$ & $\mathrm{N}$ & $\begin{array}{c}\text { Relative Risk } \\
\text { (95\% Confidence Interval) }\end{array}$ & $\mathrm{N}$ & P Value $\dagger$ \\
\hline Extremity/pelvic fracture & 0.58 (0.33 to 1.20$)$ & 1846 & 0.73 (0.39 to 1.36$)$ & 1223 & 0.63 \\
\hline Abdomen & $0.82(0.54$ to 1.35$)$ & 2261 & $0.36(0.13$ to 0.87$)$ & 808 & 0.09 \\
\hline Chest & 0.67 (0.32 to 1.37$)$ & 1373 & 0.64 (0.39 to 1.11$)$ & 1696 & 0.90 \\
\hline
\end{tabular}

*AIS = Abbreviated Injury Score. $†$ The $p$ values test the equality of treatment effects between low and high-severity associated injury subgroups.

risk of $83 \%$ of the reference $\left(t_{0}\right)$ level was estimated for treatment within the twenty-four to forty-eight-hour time frame, although this finding was not significant. With the exception of the $>120$-hour $\left(t_{4}\right)$ time frame, the Hosmer-Le Cessie test showed acceptable fit of the selected treatment model ( $p$ values for goodness-of-fit: $0.24,0.56,0.24$, and 0.028 , respectively).

In order to examine effect modification by the presence of serious associated injuries and because the categorical analysis showed similar mortality risk among the latter four treatment groups, we dichotomized treatment at twelve hours. The marginal relative risk of mortality for later treatment was 0.65 (95\% confidence interval, 0.45 to $1.04 ; \mathrm{p}=0.06$ ). For this dichotomous comparison, the data-adaptively selected logistic regression model for the treatment mechanism again showed acceptable goodnessof-fit ( $\mathrm{p}=0.54$; Hosmer-Le Cessie test). Figure 3 shows the estimated marginal mortality within groups defined by the presence of serious head or neck, chest, abdominal, or additional limb or pelvic injury, controlling for measured confounders. In general, more severely injured patients appear to benefit more strongly from delaying surgery for at least twelve hours. Only when the data were stratified with regard to abdominal injury did we see sufficient statistical evidence (Table IV) to suggest that the marginal relative risks for the two groups are different $(p=0.09)$. The estimated marginal mortality associated with delayed treatment for patients with no or low-severity abdominal injuries was $82 \%$ $(p=0.39)$ of what it would have been if they all had been managed early. This finding is in contrast to a reduction to $36 \%(\mathrm{p}=0.03)$ of the risk of mortality with early treatment had all subjects with serious abdominal injuries undergone delayed treatment. While there was a marked decrease in estimated mortality for subjects with serious head or neck injuries undergoing delayed treatment (relative risk, $0.62 ; 95 \%$ confidence interval, 0.40 to $0.99 ; \mathrm{p}=$ 0.04 ), there was insufficient statistical evidence to show a difference in effect as compared with subjects with no or low-severity head or neck injuries. Therefore, with the exception of severity of abdominal injury, it does not appear that subclassification by any of the other tested associated injuries identifies subjects who would experience a greater or lesser degree of mortality reduction from delayed treatment than that estimated for the entire sample.

The estimates from the multivariate standardized risk ratio analysis (Table III) were very similar to inverse probability of treatment-weighted estimates. This analysis estimates the effect of treatment delay for those patients who were actually managed early. This provides the most conservative estimate of treatment effect by targeting those who, given their other prognostic factors, most likely could have been managed early. Multivariate standardized risk ratios and Monte Carlo simulation (see Appendix) provided empirical and quantitative support to the robustness and validity of inverse probability of treatment-weighted estimates.

\section{$\mathrm{W}$}

Discussion e conducted an analysis of the importance of timing of definitive femoral shaft fracture fixation among subjects with multisystem trauma in the National Trauma Data Bank. Using an inverse probability of treatment-weighted analysis to estimate the marginal (i.e., the population level) risk of mortality for categorically defined treatment time, we found treatment in all but one of four delayed treatment categories (with the one exception being the twenty-four to forty-eight-hour category) to significantly lower the risk of mortality to about $50 \%$ of that expected with early treatment (less than twelve hours). We also showed that patients with serious associated abdominal injuries have greater risk reductions from delayed fixation when compared with those with less serious or no abdominal injury. These findings were consistent with, but more precisely estimated than, the results of multivariate standardized risk ratios using the early treatment group as the standard population. These findings strongly support a cautious approach to early definitive femoral shaft fracture fixation among patients with multisystem trauma, especially those with serious associated abdominal injuries.

In two large studies ${ }^{24,41}$ assessing the effect of timing of internal fixation of femoral shaft fracture, subgroups of adult patients with multisystem trauma (Injury Severity Score, $\geq 15$ ) were defined with comparable demographics, associated injuries, and crude mortality rates. Fakhry et al. ${ }^{41}$ found a significant decrease in mortality among groups that were treated later but only adjusted for the Injury Severity Score. Brundage et al. ${ }^{24}$ did not report significant differences in mortality in association with treatment time but did find significant increases in complications such as pneumonia, acute respiratory distress syndrome, and the length of hospital stay among 
The Journal of Bone \& Joint Surgery • JBjS. org Volume 91-A - Number 1 - January 2009
Delayed Fixation of Femoral Shaft Fracture in Multisystem Trauma Patients patients who were managed between two and five days after the injury. We divided the first hospital day into two periods and found a protective effect from delaying fixation even if only by twelve hours, which may afford time for some degree of resuscitation. Given that our sample was five times larger than the treated multisystem trauma subgroup in either of those studies, it is likely that an increase in power allowed more precise estimation of the protective effect of delayed treatment.

Several studies have indicated that patients with head or chest injuries may be more susceptible to the effects of early fracture fixation than patients without such associated trauma. Pape et $\mathrm{al}^{42}$ reported on a cohort of 106 patients with multisystem trauma with femoral shaft fractures (Injury Severity Score, >18) with and without thoracic trauma (Abbreviated Injury Score, $\geq 3$ ). In a stratified analysis, they reported a significant increase in the incidence of acute respiratory distress syndrome among patients with chest injuries who were managed with intramedullary nailing early (less than twentyfour hours after admission) as compared with those without chest injuries (33\% compared with $7.7 \%$ ), and a similar, but not significant, difference in mortality $(21 \%$ compared with $4 \%$ ), suggesting that patients with chest injuries might benefit from delayed treatment. The notion that intramedullary nailing potentiates the development of acute respiratory distress syndrome and further morbidity among patients who are vulnerable because of thoracic injury has been supported by human and animal studies showing embolization of marrow products during intramedullary nailing ${ }^{43-47}$; however, the clinical importance of this phenomenon continues to be debated. Several observational studies ${ }^{5,8}$ involving patients with thoracic injuries but without femoral shaft fractures as controls have demonstrated no difference in the incidence of acute respiratory distress syndrome or mortality, suggesting that it is the severity of the pulmonary injury, rather than timing or mode of fixation, that determines the likelihood of an adverse outcome. Among patients with associated head injuries, studies have shown hypotension and decreased cerebral perfusion pressure during early fracture care ${ }^{48-50}$. Still, increased mortality has not been shown when early treatment (at less than twentyfour hours) has been compared with late treatment of femoral shaft fractures ${ }^{24,41,51-53}$. While the relative risk of mortality associated with delayed treatment (beyond twelve hours) among patients with serious thoracic injuries (relative risk, 0.64; 95\% confidence interval, 0.39 to $1.11 ; \mathrm{p}=0.10$ ) approached significance and that among patients with serious head or neck injuries (relative risk, $0.62 ; 95 \%$ confidence interval, 0.40 to $0.99 ; \mathrm{p}=0.04$ ) just achieved significance in our study, there was inadequate statistical evidence to support these subgroups experiencing a greater protective effect of delayed treatment than that expected in the rest of the sample.

The only factor for which there was evidence of modification of the effect of treatment timing on mortality was the presence of serious abdominal injury. For patients with serious abdominal injuries, undergoing delayed treatment was associated with an estimated mortality risk that was 36\% that of early treatment, and this relative risk was significantly lower than that for patients without such injuries. Several studies have shown abdominal injuries to be an important risk factor for mortality and morbidity in the patient with multisystem trauma ${ }^{54,55}$. Schulman et $a .^{56}$ reported on a series of patients with blunt trauma undergoing a standardized resuscitation protocol and found only Injury Severity Score, abdominal injury (Abbreviated Injury Score, $\geq 3$ ), and extremity and osseous pelvic injury (Abbreviated Injury Score, $\geq 3$ ) to be significantly associated with prolonged occult hypoperfusion. White et al. ${ }^{55}$ reported a fivefold increase in the risk of acute respiratory distress syndrome when combined extremity and abdominal injuries were present. In the present study, patients with associated serious abdominal injuries who were managed early were likely underresuscitated and may have been particularly vulnerable to adverse outcomes in association with a definitive orthopaedic procedure that often involves substantial additional blood loss.

Early treatment in our study is a likely surrogate for treatment in an under-resuscitated state when subjects were prone to excess morbidity and mortality ${ }^{57-60}$. In a study of patients with multisystem trauma who had a femoral shaft fracture, Crowl et al. ${ }^{10}$ showed that early intramedullary fixation of femoral shaft fracture (less than twenty-four hours after admission) in the setting of occult hypoperfusion (serum lactate, $\geq 2.5 \mathrm{mmol} / \mathrm{L}$ ) led to a significant increase in postoperative complications. Hypoperfusion resulting from trauma may prime the immune system for an inflammatory response if such treatment is undertaken prior to adequate resuscitation and can lead to substantial end-organ injury ${ }^{61,62}$. The realization of this phenomenon has led to the description of so-called "damagecontrol orthopaedics," whereby definitive treatment is delayed until resuscitation of the patient has been adequately achieved $^{13,42,63,64}$. Our findings are consistent with this approach and signify the potential benefits that may be realized with delays in operative femoral fracture fixation of just twelve hours, particularly for patients with associated abdominal injuries. The current end points used to guide resuscitation, such as blood pressure, urine output, heart rate, base deficit, and serum lactate levels, are global markers that may underestimate occult tissue hypoperfusion. In the future, more sensitive measures of tissue oxygenation involving polarographic or near-infrared technologies ${ }^{65}$ and markers of inflammation and coagulation $^{66,67}$ that better reveal the physiologic condition of a patient are likely to replace simple temporal distinctions. They will provide more accurate criteria with which to determine when a patient is "ready" for definitive internal fixation of a femoral shaft fracture or other major orthopaedic injuries.

The retrospective observational nature of the present study precludes ascribing a causal effect to the timing of treatment. Unmeasured confounding by factors such as time from injury to hospital admission could bias estimates of the effect of treatment time. Moreover, missing information on measured covariates for subjects who otherwise would have been eligible for inclusion in the study sample (Fig. 1) may have introduced selection bias. While the National Trauma Data Bank includes a very large sample of trauma centers from all over the United States, it is a convenience sample. Still, this is the largest 
The Journal of Bone \& Joint Surgery $\cdot$ Jbjs.org Volume 91-A - Number 1 - January 2009
Delayed Fixation of Femoral Shaft Fracture in

Multisystem Trauma Patients cohort used for investigation of this study question, and the national representation of academic and nonacademic centers of various levels provides far-reaching generalizability of these results. The National Trauma Data Bank data provided extensive covariate information, which was used for comprehensive covariate adjustment, and robust analytical methods were used to optimize model fit and to properly estimate confidence intervals in the setting of potential correlations by treatment center. The disparity between crude and adjusted estimates (Table III), in light of higher injury severity and mortality in the later treatment groups (Table I), demonstrates the degree to which confounding by disease severity may threaten valid inferences in studies similar to ours. We employed statistically efficient analytical methods to address this bias, and these methods provided unconditional estimates of relative risk.

In conclusion, we have conducted an observational study assessing the effect of timing of definitive fixation of femoral shaft fracture in patients with multisystem trauma. We estimate an approximate $50 \%$ reduction in the risk of mortality when treatment between twelve and twenty-four hours and more than forty-eight hours is compared with treatment within twelve hours after admission; a nonsignificant reduction is estimated when treatment occurs between twenty-four and forty-eight hours. Patients with serious abdominal injuries (Abbreviated Injury Score, $\geq 3$ ) showed significantly lower estimated relative risk in association with treatment delay than did those with low abdominal Abbreviated Injury Score scores, indicating effect modification by this set of associated injuries. These results provide strong empirical evidence in support of a delayed or "damage-control" approach to definitive fixation of femoral shaft fracture among patients with multisystem trauma. While a randomized controlled trial is needed to prove the treatment effects estimated here, debate is necessary to further define a population in which such a trial would be ethical.

\section{Appendix}

eA Details of the statistical analysis are available with the eA electronic versions of this article, on our web site at jbjs.org (go to the article citation and click on "Supplementary Material") and on our quarterly CD/DVD (call our subscription department, at 781-449-9780, to order the CD or DVD).

Saam Morshed, MD, MPH

Theodore Miclau III, MD

University of California at San Francisco,

San Francisco General Hospital,

1001 Potrero Avenue, Room 3A-36,

San Francisco, CA 94110.

E-mail address for S. Morshed: morsheds@orthosurg.ucsf.edu

Oliver Bembom, $\mathrm{PhD}$

John M. Colford Jr., MD, PhD

Division of Epidemiology and Biostatistics,

University of California at Berkeley,

101 Haviland Hall MC 7358, Berkeley,

CA $94720-7358$

Mitchell Cohen, MD

M. Margaret Knudson, MD

University of California at San Francisco,

Department of Surgery,

Box 0870 (M.C.) and Box 0807 (M.M.K.),

San Francisco, CA 94143-0870

\section{References}

1. Riska EB, von Bonsdorff $H$, Hakkinen $S$, Jaroma $H$, Kiviluoto $O$, Paavilainen $T$. Prevention of fat embolism by early internal fixation of fractures in patients with multiple injuries. Injury. 1976;8:110-6.

2. Goris RJ, Gimbrere JS, van Niekerk JL, Schoots FJ, Booy LH. Early osteosynthesis and prophylactic mechanical ventilation in the multitrauma patient. J Trauma. 1982;22:895-903.

3. Johnson KD, Cadambi A, Seibert GB. Incidence of adult respiratory distress syndrome in patients with multiple musculoskeletal injuries: effect of early operative stabilization of fractures. J Trauma. 1985;25:375-84.

4. Seibel R, LaDuca J, Hassett JM, Babikian G, Mills B, Border DO, Border JR. Blunt multiple trauma (ISS 36 ), femur traction, and the pulmonary failure-septic state. Ann Surg. 1985;202:283-95.

5. Bosse MJ, MacKenzie EJ, Riemer BL, Brumback RJ, McCarthy ML, Burgess AR, Gens DR, Yasui Y. Adult respiratory distress syndrome, pneumonia, and mortality following thoracic injury and a femoral fracture treated either with intramedullary nailing with reaming or with a plate. A comparative study. J Bone Joint Surg Am. 1997;79:799-809.

6. Behrman SW, Fabian TC, Kudsk KA, Taylor JC. Improved outcome with femur fractures: early vs. delayed fixation. J Trauma. 1990;30:792-8.

7. Charash WE, Fabian TC, Croce MA. Delayed surgical fixation of femur fractures is a risk factor for pulmonary failure independent of thoracic trauma. J Trauma. 1994;37:667-72.

8. Boulanger BR, Stephen D, Brenneman FD. Thoracic trauma and early intramedullary nailing of femur fractures: are we doing harm? J Trauma. 1997;43:24-8.

9. Bone LB, Johnson KD, Weigelt J, Scheinberg R. Early versus delayed stabilization of femoral fractures. A prospective randomized study. J Bone Joint Surg Am. 1989;71:336-40.
10. Crowl AC, Young JS, Kahler DM, Claridge JA, Chrzanowski DS, Pomphrey M. Occult hypoperfusion is associated with increased morbidity in patients undergoing early femur fracture fixation. J Trauma. 2000;48:260-7.

11. Pape HC, Schmidt RE, Rice J, van Griensven M, das Gupta R, Krettek C, Tscherne $\mathrm{H}$. Biochemical changes after trauma and skeletal surgery of the lower extremity: quantification of the operative burden. Crit Care Med. 2000;28:3441-8.

12. Pape HC, Grimme K, Van Griensven M, Sott AH, Giannoudis P, Morley J, Roise O, Ellingsen E, Hildebrand F, Wiese B, Krettek C; EPOFF Study Group. Impact of intramedullary instrumentation versus damage control for femoral fractures on immunoinflammatory parameters: prospective randomized analysis by the EPOFF Study Group. J Trauma. 2003;55:7-13.

13. Giannoudis PV, Smith RM, Bellamy MC, Morrison JF, Dickson RA, Guillou PJ. Stimulation of the inflammatory system by reamed and unreamed nailing of femoral fractures. An analysis of the second hit. J Bone Joint Surg Br. 1999;81:356-61.

14. Robinson $\mathrm{CM}$. Current concepts of respiratory insufficiency syndromes after fracture. J Bone Joint Surg Br. 2001;83:781-91.

15. Rixen D, Grass G, Sauerland S, Lefering R, Raum MR, Yücel N, Bouillon B, Neugebauer EA; Polytrauma Study Group of the German Trauma Society. Evaluation of criteria for temporary external fixation in risk-adapted damage control orthopedic surgery of femur shaft fractures in multiple trauma patients: "evidence-based medicine" versus "reality" in the trauma registry of the German Trauma Society. J Trauma. 2005;59:1375-95.

16. Dunham CM, Bosse MJ, Clancy TV, Cole FJ Jr, Coles MJ, Knuth T, Luchette FA, Ostrum R, Plaisier B, Poka A, Simon RJ; EAST Practice Management Guidelines Work Group. Practice management guidelines for the optimal timing of long-bone fracture stabilization in polytrauma patients: the EAST Practice Management Guidelines Work Group. J Trauma. 2001;50:958-67. 
The Journal of Bone \& Joint Surgery $\cdot$ Jbjs.org Volume 91-A - Number 1 J January 2009
Delayed Fixation of Femoral Shaft Fracture in Multisystem Trauma Patients
17. American College of Surgeons. National Trauma Data Bank reference manual. 2005 http://www.facs.org/trauma/ntdb/ntdbannualreport2005.pdf. Accessed 2008 Sep 10.

18. Mackenzie EJ, Steinwachs DM, Shankar B. Classifying trauma severity based on hospital discharge diagnoses. Validation of an ICD-9CM to AIS-85 conversion table. Med Care. 1989;27:412-22.

19. Baker SP, O'Neill B, Haddon W Jr, Long WB. The injury severity score: a method for describing patients with multiple injuries and evaluating emergency care. J Trauma. 1974;14:187-96.

20. Brenneman FD, Boulanger BR, McLellan BA, Redelmeier DA. Measuring injury severity: time for a change? J Trauma. 1998;44:580-2.

21. Osler T, Baker SP, Long W. A modification of the injury severity score that both improves accuracy and simplifies scoring. J Trauma. 1997;43:922-6.

22. Deyo RA, Cherkin DC, Ciol MA. Adapting a clinical comorbidity index for use with ICD-9-CM administrative databases. J Clin Epidemiol. 1992;45:613-9.

23. Benjamini $Y$, Hochberg $Y$. Controlling the false discovery rate: a practical and powerful approach to multiple testing. J R Stat Soc Ser B Method. 1995;57:289-300.

24. Brundage $\mathrm{SI}$, McGhan R, Jurkovich GJ, Mack CD, Maier RV. Timing of femur fracture fixation: effect on outcome in patients with thoracic and head injuries. J Trauma. 2002;52:299-307.

25. Blow $\mathrm{O}$, Magliore L, Claridge JA, Butler $\mathrm{K}$, Young JS. The golden hour and the silver day: detection and correction of occult hypoperfusion within 24 hours improves outcome from major trauma. J Trauma. 1999;47:964-9.

26. Ferguson ND, Frutos-Vivar F, Esteban A, Fernández-Segoviano P, Aramburu JA, Nájera L, Stewart TE. Acute respiratory distress syndrome: underrecognition by clinicians and diagnostic accuracy of three clinical definitions. Crit Care Med. 2005;33:2228-34.

27. Daly LE, Bourke GJ. Interpretation and uses of medical statistics. 5th ed. Oxford: Blackwell; 2000

28. Lee AH, Fung WK, Fu B. Analyzing hospital length of stay: mean or median regression? Med Care. 2003;41:681-6.

29. Robins JM. Marginal structural models versus structural nested models as tools for causal inference. In: Halloran ME, Berry D, editors. Statistical models in epidemiology, the environment and clinical trials. New York: Springer; 1999. p 95-134.

30. Rosenbaum PR, Rubin DB. The central role of the propensity score in observational studies for causal effects. Biometrika. 1983;70:41-55.

31. Rosenbaum PR, Rubin DB. Reducing bias in observational studies using subclassification on the propensity score. J Am Stat Assoc. 1984;79:516-24.

32. Kooperberg $\mathrm{C}$, Bose $\mathrm{S}$, Stone $\mathrm{CJ}$. Polychotomous regression. J Am Stat Assoc. 1997;92:117-27.

33. Hosmer DW, Hosmer T, Le Cessie S, Lemeshow S. A comparison of goodnessof-fit tests for the logistic regression model. Stat Med. 1997;16:965-80.

34. Abbreviated Injury Score. 1990 revision. Des Plaines, IL: Association for the Advancement of Automotive Medicine; 1990.

35. Sato $T$, Matsuyama $Y$. Marginal structural models as a tool for standardization. Epidemiology. 2003;14:680-6.

36. Wang $Y$, Peterson ML, Bangsberg D, van der Laan MJ. Diagnosing bias in the inverse-probability-of-treatment-weighted estimator from violations of experimental treatment assignment. Berkeley, CA: UC Berkeley Division of Biostatistics Working Paper Series (211); 2006.

37. Efron B, Tibshirani RJ. An introduction to the bootstrap. New York: Chapman and Hall; 1993.

38. Pollard KS, van der Laan MJ. Choice of null distribution in resampling-based multiple testing. J Statist Plann Inference. 2004;125:85-101.

39. Ihaka R, Gentleman RR. A language for data analysis and graphics. J Comput Graph Stat. 1996;5:299-315.

40. R Development Core Team. R: A language and environment for statistical computing. Vienna: R Foundation for Statistical Computing; 2003. http://www.r-project.org/. Accessed 2008 Sep 10.

41. Fakhry SM, Rutledge R, Dahners LE, Kessler D. Incidence, management, and outcome of femoral shaft fracture: a statewide population-based analysis of 2805 adult patients in a rural state. J Trauma. 1994;37:255-61.

42. Pape HC, Auf'm'Kolk M, Paffrath T, Regel G, Sturm JA, Tscherne H. Primary intramedullary femur fixation in multiple trauma patients with associated lung contusion - a cause of posttraumatic ARDS? J Trauma. 1993;34:540-8.

43. Pape HC, Regel G, Dwenger A, Sturm JA, Tscherne H. Influence of thoracic trauma and primary femoral intramedullary nailing on the incidence of ARDS in multiple trauma patients. Injury. 1993;24 Suppl 3:S82-103.
44. Heim D, Regazzoni P, Tsakiris DA, Aebi T, Schlegel U, Marbet GA, Perren SM. Intramedullary nailing and pulmonary embolism: does unreamed nailing prevent embolization? An in vivo study in rabbits. J Trauma. 1995;38:899-906.

45. Pell AC, Christie J, Keating JF, Sutherland GR. The detection of fat embolism by transoesophageal echocardiography during reamed intramedullary nailing. A study of 24 patients with femoral and tibial fractures. J Bone Joint Surg Br. 1993;75:921-5.

46. Wolinsky PR, Sciadini MF, Parker RE, Plitman JD, Snapper JR, Rutherford EJ, Schulman M, Johnson KD. Effects on pulmonary physiology of reamed femoral intramedullary nailing in an open-chest sheep model. J Orthop Trauma. 1996;10:75-80.

47. Schemitsch EH, Jain R, Turchin DC, Mullen JB, Byrick RJ, Anderson Gl, Richards RR. Pulmonary effects of fixation of a fracture with a plate compared with intramedullary nailing. A canine model of fat embolism and fracture fixation. J Bone Joint Surg Am. 1997;79:984-96.

48. Jaicks RR, Cohn SM, Moller BA. Early fracture fixation may be deleterious after head injury. J Trauma. 1997;42:1-6.

49. Pietropaoli JA, Rogers FB, Shackford SR, Wald SL, Schmoker JD, Zhuang J. The deleterious effects of intraoperative hypotension on outcome in patients with severe head injuries. J Trauma. 1992;33:403-7.

50. Townsend RN, Lheureau T, Protech J, Riemer B, Simon D. Timing fracture repair in patients with severe brain injury (Glasgow Coma Scale score <9). J Trauma. 1998;44:977-83.

51. McKee MD, Schemitsch EH, Vincent LO, Sullivan I, Yoo D. The effect of a femoral fracture on concomitant closed head injury in patients with multiple injuries. J Trauma. 1997;42:1041-5.

52. Wang MC, Temkin NR, Deyo RA, Jurkovich GJ, Barber J, Dikmen S. Timing of surgery after multisystem injury with traumatic brain injury: effect on neuropsychological and functional outcome. J Trauma. 2007;62:1250-8.

53. Starr AJ, Hunt JL, Chason DP, Reinert CM, Walker J. Treatment of femur fracture with associated head injury. J Orthop Trauma. 1998;12:38-45.

54. Ziran BH, Le T, Zhou H, Fallon W, Wilber JH. The impact of the quantity of skeletal injury on mortality and pulmonary morbidity. J Trauma. 1997;43:916-21.

55. White TO, Jenkins PJ, Smith RD, Cartlidge CW, Robinson CM. The epidemiology of posttraumatic adult respiratory distress syndrome. J Bone Joint Surg Am. 2004;86:2366-76

56. Schulman AM, Claridge JA, Carr G, Diesen DL, Young JS. Predictors of patients who will develop prolonged occult hypoperfusion following blunt trauma. J Trauma. 2004:57:795-800.

57. Abramson D, Scalea TM, Hitchcock R, Trooskin SZ, Henry SM, Greenspan J. Lactate clearance and survival following injury. J Trauma. 1993;35:584-9.

58. Moore FA. The role of the gastrointestinal tract in postinjury multiple organ failure. Am J Surg. 1999;178:449-53

59. Brohi K, Singh J, Heron M, Coats T. Acute traumatic coagulopathy. J Trauma. 2003:54:1127-30

60. Hofmann S, Huemer G, Kratochwill C, Koller-Strametz J, Hopf R, Schlag G, Salzer M. [Pathophysiology of fat embolisms in orthopedics and traumatology]. Orthopade. 1995;24:84-93. German.

61. Nast-Kolb D, Waydhas C, Gippner-Steppert C, Schneider I, Trupka A, Ruchholtz S, Zettl R, Schweiberer L, Jochum M. Indicators of the posttraumatic inflammatory response correlate with organ failure in patients with multiple injuries. J Trauma. 1997;42:446-55.

62. Roumen RM, Redl H, Schlag G, Zilow G, Sandtner W, Koller W, Hendriks T, Goris RJ. Inflammatory mediators in relation to the development of multiple organ failure in patients after severe blunt trauma. Crit Care Med. 1995;23:474-80.

63. Pape HC, Hildebrand F, Pertschy S, Zelle B, Garapati R, Grimme K, Krettek C, Reed RL 2nd. Changes in the management of femoral shaft fractures in polytrauma patients: from early total care to damage control orthopedic surgery. J Trauma. 2002;53:452-62.

64. Harwood PJ, Giannoudis PV, van Griensven M, Krettek C, Pape HC. Alterations in the systemic inflammatory response after early total care and damage control procedures for femoral shaft fracture in severely injured patients. J Trauma. 2005;58:446-54.

65. Ikossi DG, Knudson MM, Morabito DJ, Cohen MJ, Wan JJ, Khaw L, Stewart CJ, Hemphill C, Manley GT. Continuous muscle tissue oxygenation in critically injured patients: a prospective observational study. J Trauma. 2006;61:780-90.

66. Pape HC, van Griensven M, Rice J, Gänsslen A, Hildebrand F, Zech S, Winny M, Lichtinghagen R, Krettek C. Major secondary surgery in blunt trauma patients and perioperative cytokine liberation: determination of the clinical relevance of biochemical markers. J Trauma. 2001;50:989-1000.

67. Giannoudis PV, Hildebrand F, Pape HC. Inflammatory serum markers in patients with multiple trauma. Can they predict outcome? J Bone Joint Surg Br. 2004;86:313-23. 